\title{
CASE REPORT: NEWBORN WITH ANORECTAL MALFORMATION
}

\author{
Agrawal T $1^{*}$, Rimal $\mathrm{HS}^{2}$
}

\section{Affiliation}

1. Lecturer, Department of Pediatrics, Birat Medical College and Teaching Hospital, Biratnagar, Nepal

2. Professor, Department of Pediatrics, Birat Medical College and Teaching Hospital, Biratnagar, Nepal

\section{ARTICLE INFO}

\section{Article History}

\section{Received : 17 June, 2018 \\ Accepted : 8 August, 2018 \\ Published : 31 August, 2018}

(C) Authors retain copyright and grant the journal right of first publication with the work simultaneously licensed under Creative Commons Attribution License CC - BY 4.0 that allows others to share the work with an acknowledgment of the work's authorship and initial publication in this journal.

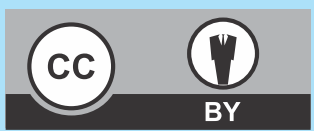

\section{CR 21}

\section{DOI: $\underline{\text { http://dx.doi.org/10.3126/bjhs.v3i2.20970 }}$}

\section{* Corresponding Author \\ Dr. Triptee Agrawal \\ Lecturer \\ Department of Pediatrics}

Birat Medical College and Teaching Hospital, Biratnagar, Nepal ORCID: https://orcid.org/0000-0001-5957-1738

\section{ABSTRACT}

Anorectal malformations are defined by the relationship of the rectum to the sphincter complex and can be classified as high and low anomaly based on whether meconium is present or absent, presence of dimple, anocutaneous reflex, sacral abnormality or presence of meconium in urine. The diagnosis should be made in the delivery room by inspecting the perineum. Meconuria with absence of anal opening invariably indicates a high malformation which requires a colostomy in the newborn period. Low malformations do not become evident until 24 hours when the meconium may show up in the perineal fistula. These defects can be managed by a perineal anoplasty without a colostomy in the newborn period. A prone cross table lateral shoot abdominal film is required if clinical information at 24 hours is insufficient to decide whether a colostomy is needed. We present a case of newborn, day 4 of life, who did not pass meconium since birth, had abdominal distension, vomiting, poor feeding and lethargy since last 2 days. Anal area showed pigmentation with presence of median raphe, anal dimple and slightly formed anal opening. Baby was initially thought as a case of low type imperforate anus. On further evaluation, was found to have meconuria too. Invertogram done showed high type defect. Rest of the examination was normal. Supportive therapy was initiated and baby underwent transverse loop colostomy for high type imperforate anus on day 5 of life. So it is always advisable to confirm the type of anorectal malformation both clinically and by doing required investigation before deciding for any operative intervention like colostomy or anoplasty, as clinical examination and investigation may not correlate in all occasions. Evaluation should also include screening out for associations and other sacral anomalies.

\section{KEYWORDS}

Anorectalmalformation, infant, newborn.

\section{Citation}

Agrawal T, Rimal HS. Case Report: Newborn with Anorectal Malformation. BJHS 2018;3(2)6:500-503. 


\section{INTRODUCTION}

Anorectal malformations are defined by the relationship of the rectum to the sphincter complex which includes a mass of muscle fibres surrounding the ano rectum. ${ }^{1}$ It includes varying degree of stenosis to complete atresia. ${ }^{1}$ The incidence is 1 in 3000 live births. ${ }^{1}$ Imperforate anus is a congenital defect in which child is born without an anal orifice. ${ }^{2}$ Its presentation varies in males and females. In boys, the rectum terminates either above (high malformation) or below (low malformation) the levator ani. ${ }^{2}$ In high malformations, the rectum terminates in the urinary tract through a recto urinary fistula. ${ }^{2}$ In low malformations, the rectum terminates within about a $\mathrm{cm}$ from the skin, there is no recto urinary communication and often the meconium shows up in the perineum through a small opening (perineal fistula) either at the site of normal anus or along the median raphe in the scrotum (ano cutaneous fistula). ${ }^{2}$

High anomaly is usually indicated clinically when there is no meconium in the perineum at $24 \mathrm{hrs}$, flat bottom, absent anal dimple or pigmentation, absent ano cutaneous reflex, sacral abnormality and presence of meconium in urine. ${ }^{3}$ Low anomaly is suggestive when there is a good perineum, pigmented dimple, ano cutaneous reflex, visible fistula in the perineum, bucket handle deformity- a bridge of skin over the anal site under which an instrument can be passed and meconium can be seen under the skin. ${ }^{3}$

The diagnosis should be made in the delivery room by inspecting the perineum-no anal opening is found. ${ }^{3}$ The next step is observing for passage of meconium in urine. ${ }^{3}$ Meconuria with absence of anal opening in the perineum invariably indicates a high malformation which requires a colostomy in the newborn period. ${ }^{3}$ Low malformations do not become evident until 24 hours when the meconium may show up in the perineal fistula. ${ }^{3}$ These defects can be managed by a perineal anoplasty without a colostomy in the newborn period. ${ }^{3}$ Sometimes if there is doubt clinically, a prone cross table lateral shoot abdominal film is required if clinical information at 24 hours is insufficient to decide whether a colostomy is needed. ${ }^{2}$ The distance of rectal gas from the skin marker is measured. If less than $1 \mathrm{~cm}$, a perineal anoplasty is performed. If more than $1 \mathrm{~cm}, a$ colostomy is performed. ${ }^{2}$

Associated anomalies are seen in $50-60 \%$ cases, out of which nearly two thirds are genitourinary, $25 \%$ vertebral, $20 \%$ cardiac and $10 \% \mathrm{GI}^{4}{ }^{4} 15 \%$ have VACTERL or CHARGE association. ${ }^{4}$ High malformations have higher chances of associated malformations. $^{5}$

We present a case report of a newborn male who presented to our hospital, was initially suspected with low type imperforate anus, however investigations and further evaluation revealed it to be high type malformation, so baby underwent colostomy and subsequent management.

\section{CASE}

Newborn, day 4 of life, male, term , normal vaginal delivery with a birth weight of $3 \mathrm{Kg}$ presented with complains of abdominal distension, vomiting, poor feeding and lethargy since last 2 days. Baby did not pass stool since birth, was passing urine normally. Antenatal history normal. On examination baby was lethargic, poor activity. AF was normal. Baby had normal cardiovascular and respiratory examination. Abdominal examination revealed distended abdomen with normal umbilical stump. Genitourinary

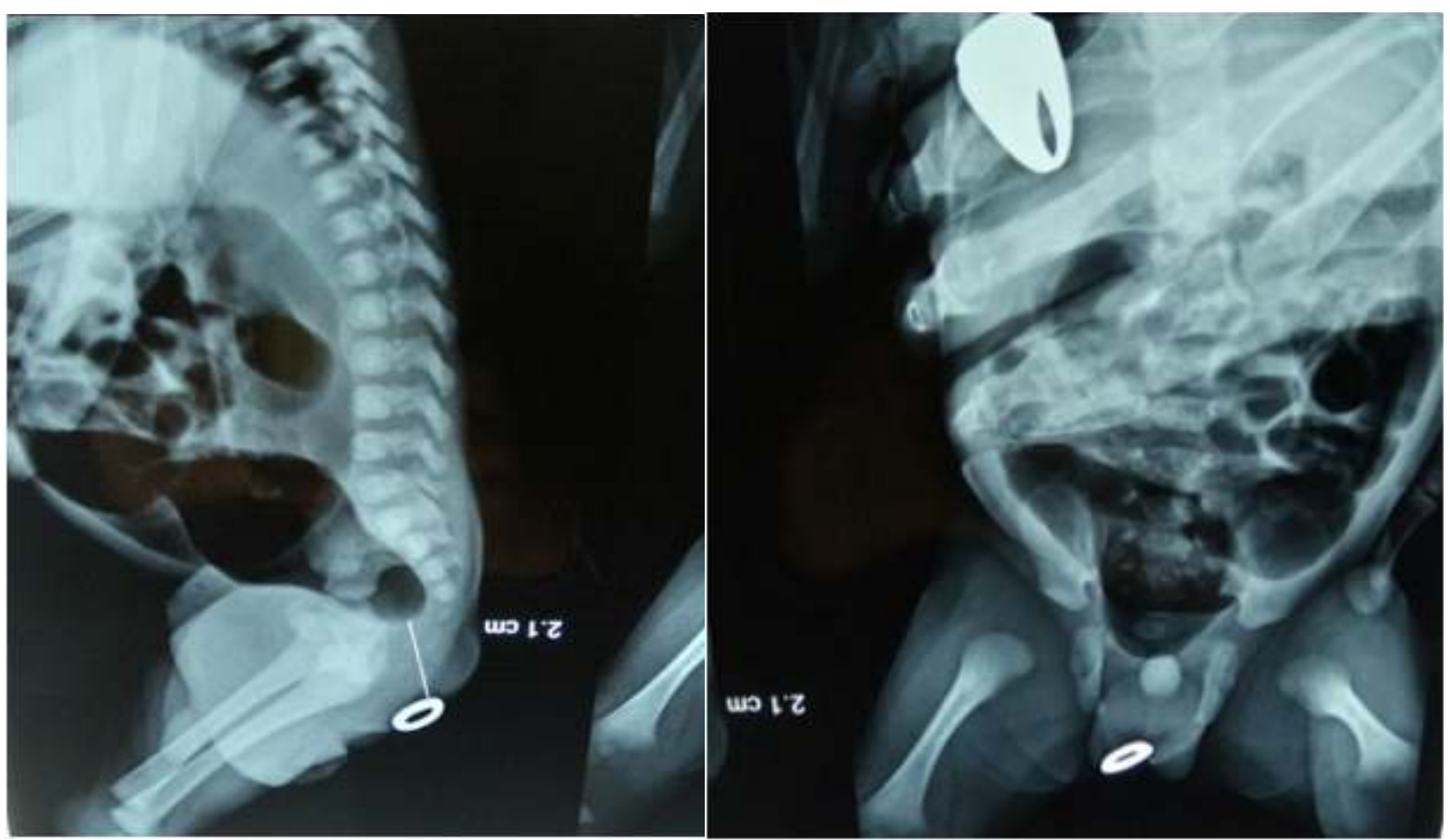

Fig1 and 2: Invertogram showing the distance between rectal shadow and the skin (more than $1 \mathrm{cms}$ ) 
examination revealed normal genitals, scrotum and testes was normal. Anal area showed pigmented anal area with presence of median raphe, anal dimple and slightly formed anal opening. However on passing naso gastric tube, the tube could not be passed into the opening and would get tilted. There was appearance of bucket handle deformity with presence of anocutaneous reflex. Baby was initially thought as a case of low type imperforate anus. However on further evaluation baby was found to have meconuria too. On same day underwent an invertogram which showed the distance between anus and rectal gas shadow to be $2.1 \mathrm{cms}$ suggestive of high type defect.

Supportive therapy was initiated. Investigations revealed normal blood counts, mildly elevated CRP and normal

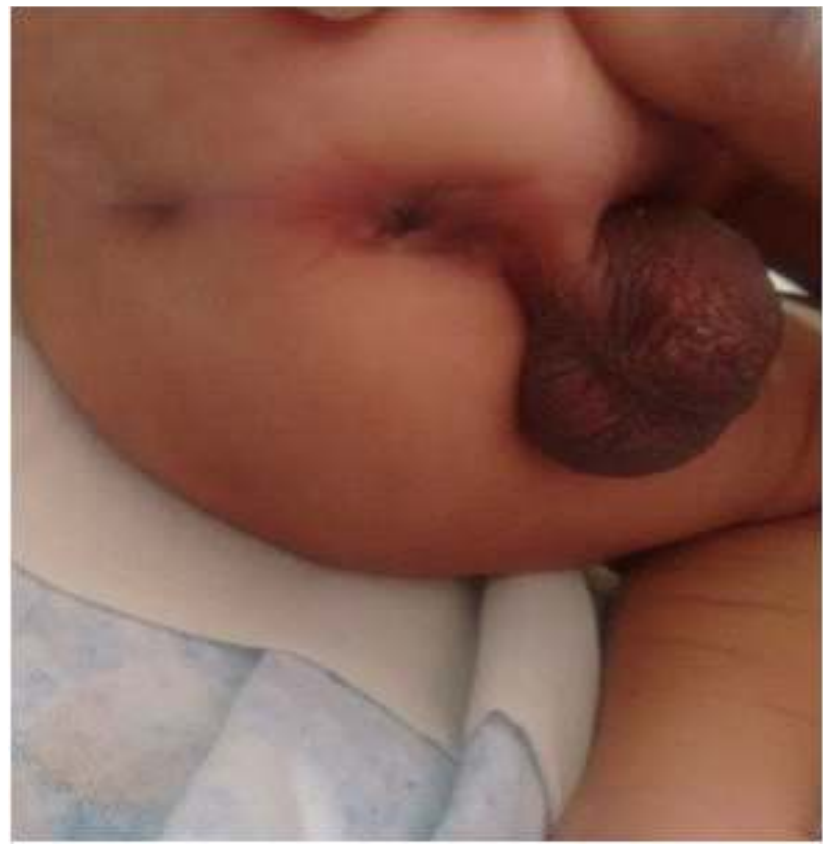

Figure 3: Figure showing anal area of 4 day old newborn, note the presence of anocutaneous fold, mild pigmentation and median raphe. Also there is presence of sacral dimple.

sugars. Surgical consultation was taken. Baby underwent transverse loop colostomy for high type imperforate anus on day 5 of life. Post operatively, hemodynamics were stable. Baby was started on feeds gradually, became active, was hemodynamically stable throughout. He was also screened for other congenital anomalies including renal, cardiac defects, limb defects, spinal and cranial USG for congenital anomalies, vertebra for defects. No evidence of VACTERL and CHARGE association was present. Baby had capillary hemangiona in form of reddish erythematous rash over forehead. Caretakers were taught colostomy care and plan is to follow up with pediatric surgeon and plan definitive surgery.

\section{DISCUSSION}

Usually imperforate anus both high and low type anomaly are diagnosed based on clinical manifestations, history of passage of meconium in urine and perineal examination. Good clinical evaluation and a urinanlaysis provide enough data in $80-90 \%$ of patients to determine the need for a colostomy. ${ }^{6}$ The presence of meconium in the urine and a flat bottom are considered indications for the creation of a colostomy. ${ }^{6}$ Clinical findings consistent with the diagnosis of a perineal fistula represent an indication for an anoplasty without a protective colostomy. ${ }^{7}$ In our case, the newborn infant had clinical features suggestive of low imperforate anus, however investigation and also presence of meconuria was in favour of high anorectal malformation. ${ }^{8}$ Eventually baby underwent a colostomy following which meconium was passed. Baby was started on breast feeds and supportive care continued. Baby was discharged on day 7 of hospital

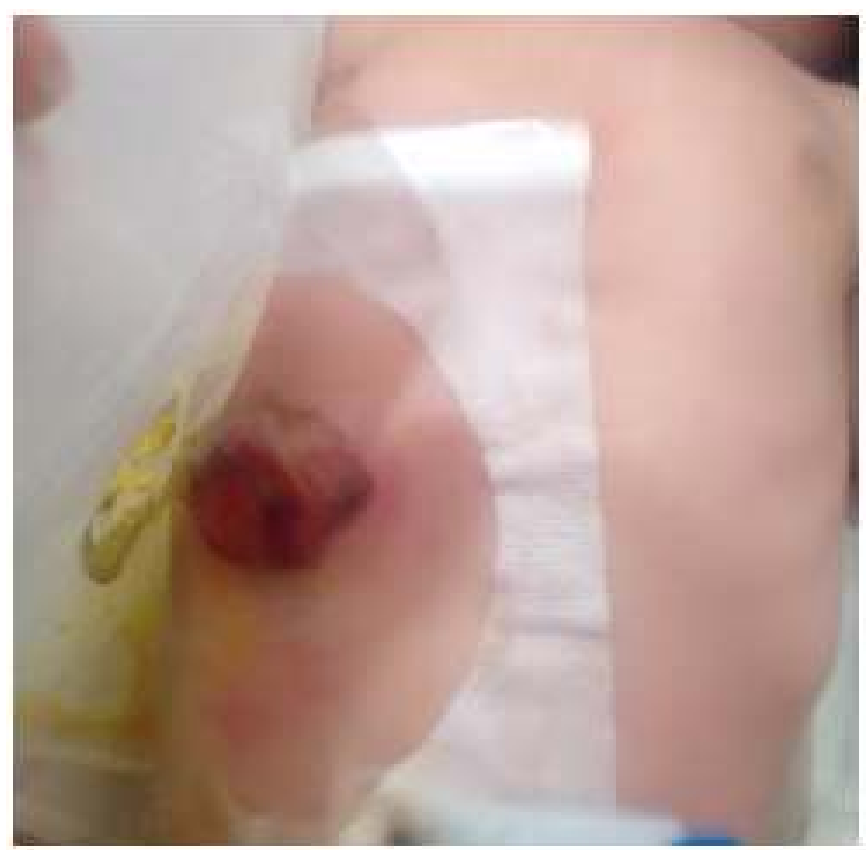

Figure 4: Shows colostomy done for same on day 4 of life, after which supportive care was continued using colostomy bag.

stay and colostomy care has been advised at home until definitive surgery.

\section{CONCLUSION}

It is always advisable to confirm the type of anorectal malformation both clinically and by doing required investigation before deciding for any operative intervention like colostomy or anoplasty. Evaluation should also include screening out for CHARGE and VACTERL association and other sacral anomalies. Every newborn should have thorough examination for congenital anomalies including presence of anal opening. Passage of meconium within 24 hrs should be ensured, failing to do so further evaluation should be done.

\section{FINANCIALDISCLOSURE}

None 


\section{REFERENCES}

1. Levitt, Marc A, Pena A. Anorectal Malformations.Orphanet J. Rare Dis 2007;2:33 doi:10.1186/1750-1172-2-33

2. Herman, Richard S, Teitelbaum D H. Anorectal Malformations. Clinics in Perinatology 2012;39: 403-22. doi:10.1016/j.clp. 2012.04.001

3. Gangopadhyay, Narayan A, Pandey V. Anorectal Malformations. J Indian Assoc Pediatr Surg. 2015; 20: 10. DOI: 10.4103/09719261.145438

4. Chesley, Patrick M, Melzer L, Bradford M C, Avansino. Association of Anorectal Malformation and Intestinal Malrotation. Am. J. Surg 2015;209: 907-12. DOI: 10.1016/j.amjsurg.2014.12.028
5. Rintala, Risto J. Congenital Anorectal Malformations: Anything New?.Journal of Pediatric Gastroenterology and Nutrition 2009;4: S79-82. doi: 10.1097/MPG.0b013e3181a15b5e

6. Bhatnagar S. Anorectal Malformations (Part 1). Journal of Neonatal Surgery 2015;4:7. PMID:26034719.

7. Choudhary P, Bagga A, Chugh K, et al. Principles of Pediatric and Neonatal Emergencies. $3^{\text {rd }}$ ed. New Delhi Jaypee;2011 ISBN 97881844895078 Spitz L, Coran AG. Operative Pediatric Surgery. $6^{\text {th }}$ ed. London: Hodder Arnold. 2006 PMCID: PMC2728340

8. Ziegler MM, Aziz Khan RG, Weber TR, Operative Pediatric Surgery. International ed. New York: McGraw-Hill;2003 